DOI 10.15393/j9.art.2015.3446

УДК 821.161.1.09“18“-3

Клавдия Валерьевна Сизюхина

Петрозаводский государственный университет

(Петрозаводск, Российская Федерация)

klasizz@yandex.ru

\title{
ГАЗЕТНЫЕ ФРАГМЕНТЫ В СТРУКТУРЕ ДНЕВНИКОВ А. М. ДОСТОЕВСКОГО
}

Аннотация: В статье рассматриваются особенности функционирования газетных жанров в структуре дневников А. М. Достоевского. Взаимодействие жанров оказывается возможным за счет художественнопоэтического своеобразия дневникового текста. А. М. Достоевский использует газетные публикации для придания творческой динамики повествованию. Во-первых, он соотносит судьбы родных людей (сестры В. М. Карепиной, брата Ф. М. Достоевского, старшего сына Александра) с историческими реалиями эпохи. Тогда газетные вклейки, приводимые на страницах дневников, носят биографический характер и символизируют синкретизм внутреннего психологического времени автора с общественным. Расширяя стилистическое пространство дневникового текста, А. М. Достоевский сообщает свое эмоциональное состояние вовне, переводит поэтику частного авторского высказывания на новый уровень - публичности. При этом печатные вставки личного свойства не нарушают сюжетно-тематическую линию дневниковых заметок, а дополняют их содержание. Во-вторых, А. М. Достоевский включает в повествование и цикл газетных публикаций, которые опосредованно соприкасаются с его семейной историей. Они освещают внешние панорамные события жизни, например: международная хроника, фенологические заметки («бюллетени природы Д. Кайгородова»), воспоминания о литераторах, военных деятелях прошлого, членах королевских фамилий, различные статистические данные и т. д. Таким образом, газетные заметки (как биографические, так и общего плана) расширяют социокультурный контекст дневников А. М. Достоевского, а личная история автора приобретает особое значение в жизни эпохи.

Ключевые слова: дневник, газета, заметка, жанр, стиль, А. М. Достоевский, В. М. Карепина, Ф. М. Достоевский

невниковому тексту свойственно стилистическое
многообразие: он может объединять в себе фрагменты
различных жанров - хроникальные экскурсы, реминисцен-
ции, описания сновидений, переложения ярких анекдоти-
ческих ситуаций (случаев из жизни), поэтические отрывки, 
письма, публицистические и путевые заметки, фенологические наблюдения и проч. К примеру, хорошо известно суждение одного из теоретиков жанра дневника М. Ю. Михеева. Исследователь демаркирует понятия собственно дневника и дневникового текста, включая в состав последнего широкий спектр сопутствующих жанровых разновидностей [6], [7]. Правда, исходя из подобной динамичной поэтики дневникового жанра, М. Ю Михеев не рассматривает дневник как самостоятельный текст, именуя его «пред-текстом»: «...у дневника оказывается некий промежуточный статус: это еще не то, что следовало бы оформить как текст литературы, но уже и не то, что было эфемерной, сразу же исчезающей <..> речью. Иными словами, это почти-текст, недотекст, около-текст, или пред-литература... (курсив автора. K. С.)» $[6,136]$. Мы же склонны определять дневник в качестве автономной жанровой единицы, а детерминированные М. Ю. Михеевым «пред-текстуальные» свойства приравниваем к интертекстуальной вариативности жанра.

В данном исследовании речь пойдет об особенностях функционирования публицистического жанра в контексте дневникового повествования Андрея Михайловича Достоевского. Прежде всего стоит отметить, что дневники А. М. Достоевского имеют не игровую, а документальную природу. Иными словами, они являют собой пример дневника нелитературного, то есть заведомо не предназначенного автором для публикации или какого-либо широкого освещения ${ }^{1}$. По мнению А.С. Рейнгольд, в первую очередь нелитературный дневник отличает «свободная, сбивчивая манера письма». В отличие от своих литературных аналогов, он не подразумевает вымышленной («фикциональной») творческой стилизации, то есть «непосредственен». Основными признаками нелитературных дневников являются реализм, интимность и достоверность (в том смысле, что этим текстам читатель верит больше, чем литературно обработанным) [8, 128]. Жанр публицистики также характеризуется документальностью и информативностью материалов. В частности, это касается его наиболее популярной жанровой модификации - газетно-публицистической. Сближение жанров нелитературного дневника и газетной заметки 
происходит именно на основании сродной контекстуальной фактографичности: «Публицистическая речь фактографична, это качество является стилевой доминантой» $[2,36]^{2}$. Тогда, казалось бы, отличительным свойством двух жанровых систем должен выступать коммуникативный принцип интимности/публичности. Однако и здесь стилистические установки жанров не противоречат друг другу, а обоюдно взаимоуравновешивают и взаимодополняют особенности авторской коммуникации. Во-первых, речевое пространство дневникового текста социализируется, то есть автор, прорываясь за рамки частных репрезентаций, оказывается вовлеченным в процесс исторического развития социума, наблюдает за панорамными событиями внешней жизни. Стилистика дневника становится более информативной. Вовторых, публицистический текст приобретает жанровые черты дневникового: газетная заметка, вошедшая в мемуарное повествование, все-таки существует не отстраненно как своего рода стилистическая маргиналия, а является продолжением личностного высказывания автора, созвучна духу его творческой установки ${ }^{3}$.

В дневниках А. М. Достоевского газетно-публицистические заметки играют особую роль. С одной стороны, они подчеркивают фактологичность содержания, еще больше утверждают сдержанную лаконичную стилистику текста, а с другой, сообразуются с семейной историей автора. Все представленные в дневниках А. М. Достоевского газетные заметки мы условно разделили на две группы: иллюстрирующие ход общего исторического времени (описывают ситуации, не относящиеся к жизни автора) и биографически сопряженные с окружением автора (посвящены памятным для него датам, близким людям). Если говорить о композиционной структуре рукописных и газетных заметок, то последние помещаются в основное пространство текста. Начиная новую дневниковую «книгу для заметок» (как именует свои дневники сам автор), А. М. Достоевский чаще всего сначала наполняет ее газетными вклейками, а потом уже делает текущие поденные записи. Впервые газетные фрагменты появляются на страницах дневника 1891-1892 годов ${ }^{4}$ и с этого 
момента становятся неизменными текстологическими спутниками последующих дневниковых описаний. Каждая печатная вставка обязательно сопровождается авторской ремаркой с указанием названия источника и его выходных данных (номера и даты выпуска). К слову, почти все заметки, приводимые А. М. Достоевским, принадлежат газете «Новое Время». Отталкиваясь от ряда дневниковых комментариев, можно сделать вывод, что Андрей Михайлович симпатизировал литературному слогу главного редактора «Нового Времени» А. С. Суворина, его умению вести полемику корректно и остроумно. Газетная рубрика Суворина «Маленькие письма» часто получала положительный отклик со стороны А. М. Достоевского. К примеру: «Воскресенье 10 го Мая <..> Въ посльднихъ газетахъ меня очень заинтересоваль инцидентъ между Нижегородскимъ Губернаторомъ и Газетою Гражданинъ5. Такъ что я вырьзаль изъ газетъ и наклеиль въ эту книгу какъ сообщеніе объ инцидентъ (среди газетъ и журналовъ) такъ и маленькое письмо Суворина, въ которомъ Губернаторь Барановъ, - по моему, потерпьль таки заслуженное имъ fiasco» (ДН1891-1892, 74), «Пятница 17о Декабря <..> Дома засталь однь только газеты, чтеніемъ которыхъ и занимался все посль объденное время и вечеръ.

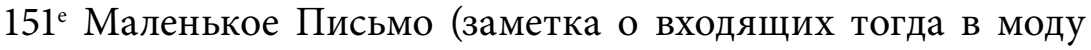
конкурсах красоты. - К. С.) такъ мнь понравилось, что я его вырьзаль и наклеиль сюда» (ДН1893-1894, 88 об.), «Среда $27^{\text {го }}$ Декабря <...> досидъль до 9 ту отъ субботы. Маленькое письмо Суворина, восхитительно! (о конфликте между дворянством и губернатором в г. Твери. - К. С.)» (ДН1894-1895, 125), «Пятница 29го Декабря <..> Не правда ли, хорошо, наклеенное на этой страницъ Маленькое письмо Суворина? Дивно хорошо!.. Только такою хлесткою сатирою и можно дьйствовать на нашихъ глупо-красныхъ, на русскихъ горе-политиковъ!!!... Честь и хвала старику Суворину!!!.. (на ту же тему. - К. С.)» (ДН1894-1895, 125 об. - 126).

Газетные публикации, иллюстрирующие перипетии внешней социальной жизни, стилистически синкретичны ежедневным дневниковым записям А. М. Достоевского. Они 
акцентируют хроникальность, процессуальную сюжетную стремительность, смену описываемых планов, свойственную жанру дневника. В какой-то мере печатные заметки эквивалентны путевым описаниям: публицистические отрывки, расположенные в хронологическом порядке и маркируемые автором, формируют подобие путеводной текстологической нити, исторического вектора, по которым субъект незримо совершает свое путешествие. Большой любовью у А. М. Достоевского пользуются: 1) натуралистические зарисовки Д. Кайгородова (так называемые «бюллетени природы», информирующие читателя о метаморфозах в животном и растительном мире), 2) рассказы об известных людях прошлого и связанных с ними событиях (к примеру, воспоминания Александры Осиповны Смирновой-Россет (18091882), фрейлины императорского двора, которая была дружна с А. С. Пушкиным, В. А. Жуковским, Н. В. Гоголем и другими литераторами того времени), 3) новости заграничной жизни, 4) различные статистические данные, 5) хозяйственно-бытовые сведения (рубрика «обиходная рецептура»).

Особенное положение среди встречающихся в дневниках А. М. Достоевского газетных пассажей отводится заметкам биографического характера. В них упоминаются дорогие и памятные сердцу автора имена - сестры Варвары Михайловны Карепиной (1822-1893, урожд. Достоевская, состояла в браке с Правителем канцелярии Московского военного генерал-губернатора П. А. Карепиным), брата Федора Михайловича Достоевского, старшего сына Александра (1857-1894). Тяжелое впечатление оставляют заметки, посвященные сестре и сыну Андрея Михайловича, так как они омрачены скорбными событиями в жизни автора. 21 января 1893 года в собственном доме по 1-му Знаменскому переулку в Москве была зверски убита и подожжена В. М. Карепина, а 6 октября 1894 года после продолжительного нервного расстройства в клинике душевных болезней при Императорской военно-медицинской академии умирает Александр Андреевич Достоевский. Публицистические вставки, обрамляющие интимную семейную эстетику текста, символизируют психологический компромисс между стремлением автора камерно живописать судьбы родных ему людей и возможностью 
обнародовать наиболее значимые (драматические или торжественные) моменты их жизни. Кроме того, в данном случае газетные заметки возлагают на себя функцию своеобразного стилистического камертона, который улавливает общее мортальное настроение рукописных эпизодов и транслирует подавленное психологическое состояние автора читателю. В обратную сторону это можно интерпретировать как внутреннее эмоциональное освобождение А. М. Достоевского: он сообщает свою боль вовне не только через основной текст записи, но и посредством художественных инструментов публицистического жанра. Наподобие фотографических карточек, газетные заметки оживляют память об ушедших родственниках, рисуют портреты их личностей, опосредованно затрагивают ключевые стороны характера. По словам В. Г. Костомарова, стилистическое своеобразие газетнопублицистического жанра базируется на взаимодействии текстологических клише, устойчивых речевых формул с экспрессивностью авторского высказывания. Подобная художественная ассимиляция в той или иной мере присуща всем речевым стилям, но в пределах газетной публицистики этот принцип возведен в жанровый канон: «...самое главное в общественной эстетике, в том, что понимается как красивое (выделено автором. - К. С.)» $[4,12]$. Довольно часто литературная эмоциональность слога принимает формы неоправданной (иногда фальсифицированной) деструкции образов рассматриваемых в заметках персоналий. Так незамедлившая последовать за убийством В. М. Карепиной статья в январском номере газеты «Московский Листок» (№ 22, 1893 г.) под заглавием «Жертва скупости» вызвала справедливое негодование в душе А. М. Достоевского. Автор характеризует ее не иначе как «гнусная статейка» и отправляет в редакцию издания ответное «протестующее письмо»: «Воскресенье 24 물 Января <...> Между тъмъ гнусная статейка о смерти сестры В. М. въ Московскомъ Листкъ № 22, которую я прочель вчера, подъ заглавіемъ «Жертва Скупости», - продолжала сильно волновать меня. Какое имъла право редакція озаглавливать такъ причину смерти сестры?! - Обдумавъ дъло, я рбшился написать протестующее письмо для напечатанія въ той же газеть Московскій 
Листокъ. - Ежели я не вступлюсь за свъжую могилу покойной, - то кто же вступится подумалъ я» (ДН1893-1894, 5 об.). Однако исход газетной полемики оказался не в пользу Андрея Михайловича. В дневниковой записи от 29 января 1893 года автор сокрушенно констатирует: «Сперва обычнымъ путемъ дошелъ до бульвара и мимо Казанскаго Собора прошель въ лавку Овсянникова. - Тамъ недолго посидълъ. - Во время моего тамъ пребыванія туда принесли газеты и я увидавъ № Московскаго Листка, попросилъ его пробъжать. Пробъгая увидълъ, что мое письмо въ этомъ Номерь $28^{\mathrm{mb}}$ отъ $28^{\text {го }}$ Января напечатано. - Но какъ напечатано въ извлеченіи. - Архимошенникъ Пастуховъ выпустилъ всё то что было ьдкаго относительно его, а напечаталъ только (правда моими словами) некрологъ покойной!» (ДН1893-1894, 6 об.). Приведенная цитата, начиная со слов «пробегая увидел» и до конца, слева на полях отмечена карандашом вертикальной линией с пометой $\mathrm{NB}$, что косвенно говорит об особом эмоциональном состоянии автора, расстроенного своей неудачей. К сожалению, А. М. Достоевский не перенес озвученные нами свидетельства газетной полемики с редакцией «Московского Листка» на страницы дневников. Видимо, некомпетентный и небрежный тон публикаций повлек столь сильное отторжение автора, что заставил отказаться от включения их в содержание дневникового текста. Однако в заключении дневника 1893-1894 годов А. М. Достоевский помещает три газетные вырезки, касающиеся дела об убийстве В. М. Карепиной: 1) «Изъ газеты “Гражданинъ”» (ДН1893-1894, 130 об.), 2) «Изъ № 35ํㅡㄴ Московскаго Листка отъ $4^{\text {го }}$ Февраля 1893 года» (ДН1893-1894, 131), 3) «Изъ газеты «Русскія Въдомости<»> № 78 отъ 21을 Марта 1893 года» (ДН1893-1894, 132 об. - 133, заметка занимает весь разворот). О двух последних газетных сообщениях упоминается в основном тексте дневниковых записей: фрагменты 1) от 5 февраля 1893 года («Въ другомъ же пакетъ былъ № Московскаго Листка за № 35й съ подробнымъ описаніемъ страшнаго убійства» (ДН1893-1894, 8), 2) от 22 марта 1893 года («Въ $12^{\text {гь }}$ ко мнъ заходилъ Треппель и принесъ два № Московскихъ Газетъ а именно Русскія Въдомости 
№ 78 и Московскій Листокъ № 80; объ отъ 21은 Марта. Въ объихъ напечатаны краткіе отчеты объ Уголовномъ дълъ, разбиравшемся въ Московскомъ Окружномъ Судъ $20^{\text {ro }}$ Марта по убійству сестры Варвары Михайловны Карепиной» (ДН1893-1894, 19)).

Таким образом, несмотря на то, что композиционно заметки вынесены за пределы основного текстологического высказывания, они все равно сопряжены с сюжетной канвой повествования. Вступительный же абзац первой заметки отсылает читателя к публикационной риторике автора с «Московским Листком»: «Недъли двъ тому назадъ, въ собственномъ домъ сгоръла, по неосторожности, Варвара Михайловна Карепина, родная сестра покойнаго писателя Ө. М. Достоевскаго. Сообщая объ этомъ происшествіи, нъкоторыя газеты позволили себъ озаглавить эти сообщенія “Жертва скупости”, такъ какъ скончавшаяся Карепина вела скромную жизнь, отказывая себъ неръдко почти въ необходимомъ, на что немедленно послЂдовало возраженіе со стороны брата покойной Андрея Михайловича Достоевскаго» (ДН1893-1894, 130 об.).

Сюжетно-композиционное значение газетных эпизодов с участием В. М. Карепиной не исчерпывается лишь их соотношением с общей стилистической динамикой текста. Они также способствуют раскрытию образа автора, делая его характер более рельефным, многогранным. Ранее в дневниковых записях А. М. Достоевского можно встретить достаточно резкие комментарии в адрес В. М. Карепиной, в которых автор с горечью описывает положение дел сестры и порицает ее за скупость и стремление к наживе («Понедъльникъ $17^{\text {ro }}$ Апрьля $<1889><\ldots>$ Но Боже мой! - что это за жизнь!! Отказывать себъ во всемъ даже необходимомъ, и все копить, копить и копить!!» (ДН1888-1889, 55 об.)). В своих наблюдениях автор прибегает и к весьма эмоциональным лексическим оборотам, когда самые неприятные качества внутреннего мира В. М. Карепиной получают развитие в ее внешнем облике. К примеру, вот какое впечатление оставляет у А. М. Достоевского встреча с сестрой в 1887 году: «Въ послъдніе 5 льтъ, что я не видалъ сестры, она очень постаръла, 
и хотя у нея нътъ ни однаго съдаго волоса; но она согнулась какъ старуха, такъ что у нея сдълалось въ родъ горба на спинь!» (ДН1884-1885(1887), 49). Обратим внимание на колоритные портретные зарисовки: «согнулась как старуха», «сделалось вроде горба на спине».

Узнав о смерти сестры, А. М. Достоевский отступает от некогда высказанных им критических суждений и пытается реабилитировать ее образ. Знаковая полемика с «Московским Листком» - прежде всего попытка объяснить самому себе (не только отстоять репутацию сестры в глазах общественности) нравственные трансформации, произошедшие в душе Варвары Михайловны.

На одном из последних листов дневника 1894-1895 годов вклеены три газетных отрывка-некролога в память Александра Андреевича Достоевского (ДН1894-1895, 133): 1) «Изъ га-

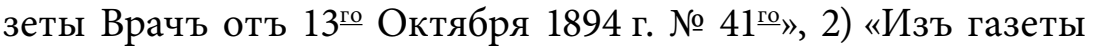
Новое Время (современно)», 3) «Изъ газеты Петербургскій Листокъ № 277믄 за 1894 годъ». Как и в случае с В. М. Карепиной, сюжетно-композиционные предпосылки для появления данных печатных фрагментов содержатся в основном тексте записей. В записи от 30 октября 1894 года читаем: «Въ семъ посльднемъ (письме. - К. С.) Андреюшка (младший сын А. М. Достоевского. - К. С.) приложиль 2 некролога о Сашъ; одинъ выръзанный Петерб. Листокъ изъ № 277 за сей 1894 г; а другой болъе серьёзный изъ газеты Врачъ отъ 13을 Октября 1894 года за № 41, доктора Шавловскаго» (ДН1894-1895, 38 об.). К газетной заметке, обозначенной как «Изъ газеты Новое Время (современно)», по всей видимости, отсылает нас следующая дневниковая ремарка от 13 октября 1894 года: «Въ газеть № 6686, помбщенъ очень симпатичный некрологъ о Сашъ, который я прочель обливаясь слезами!» (ДН1894-1895, 34 об.). Отправной точкой всего рассматриваемого цикла этих скорбных публикаций выступает запись, сделанная А. М. Достоевским 7 октября 1894 года, в тот день, когда он, получив телеграмму от родственников, узнает о кончине Александра: «Распечатавъ телеграмму я прочель сльдующее: “Саша скончался 6 7 час. 30 мин. вечера, похороны воскресенье. - Рыкачевы 
Достоевскій". Еще не распечатывая телеграммы я зналъ что она извъщаетъ о смерти страдальца!!! Но несмотря на то всё таки она меня порадовала! И такъ всё кончено,... дорогого Саши уже не существуетъ!!!...» (ДН1894-1895, 34).

Любопытен тот факт, что все газетные заметки, корреспондирующие с угнетенным, подавленным состоянием автора, находятся вне основного поля дневникового текста. Стилистически, идейно-тематически они входят в состав корпуса каждодневных записей, поскольку информационно и эмоционально взаимодействуют с авторским словом. Тогда почему А. М. Достоевский оставляет текущие газетные вырезки «за скобками», отстраняется от них, в первую очередь, как читатель, пряча где-то в глубине своего повествования? Выше для обозначения творческой потребности автора в использовании газетных публикаций внутри дневникового текста мы использовали понятие «психологический компромисс». Здесь внутренняя мотивация А. М. Достоевского пережить переломные драматические моменты семейной истории в одиночестве, без общественного соучастия диктует такую "разорванную» композицию основных записей с изложением случившихся тягостных событий и освещающих их газетных заметок. Для автора утрата близких людей - это личная трагедия, а не новостной инцидент или повод для сплетен в одной из газетных рубрик.

Среди материалов дневников А. М. Достоевского присутствуют и публицистические заметки, рассказывающие о некоторых эпизодах из жизни брата Федора Михайловича. Им автор отводит место в основном текстологическом пространстве дневниковых наблюдений. Например, в цепочке мартовских записей 1893 года обнаруживается фрагмент из газеты «Новое Время» от $3^{\text {го }}$ марта 1893 года (№ 6110) (ДН1893-1894, 14 об.). Этот небольшой отрывок передает воспоминания «адъютанта дивизионного генерала Дометти» г. Иванова от встречи его в 1855 году с Ф. М. Достоевским, служившим тогда рядовым в Семипалатинске: «Достоевскій пришелъ къ г. Иванову <...> и просилъ его помочь ему представить черезъ этого генерала корпусному командиру Гасфорту стихи, написанные имъ на смертъ императора Николая Павловича и посвященные его августьйшей супругъ 
императрицъ Александръ Өеодоровнъ». Текст статьи очень благожелателен, и сама ситуация, представленная в ней, окутана атмосферой доброй грусти, сентиментальной ностальгии. Иванов сообщает о впечатлении, произведенном стихами Ф. М. Достоевского на генерала Дометти: «въ добрыхъ глазахъ старика блеснули слезы <..> - Скажите ему (Ф. М. Достоевскому. - К. С.), - отвъчалъ онъ, повернувшись въ сторону, чтобы я не замътилъ его слезъ, - что стихи его прекрасны и я буду лично просить корпуснаго командира представить ихъ вдовствующей императрицъ».

В дневниковых записях за июнь 1895 года имеет место еще одна интересная, даже курьезная газетная заметка, в которой фигурирует имя Ф. М. Достоевского (ДН1894-1895, 84 об.). Как обычно, публикации предшествует авторская

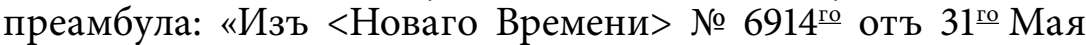
1895 года». В заметке воспроизводится краткая официальная биография писателя, источник которой семипалатинский «временной билет» на жительство Ф. М. Достоевского, выданный ему в 1859 году. Курьезность изложенному придает ошибка, вкравшаяся в фактический материал: «Былъ въ отставкъ съ 19 октября 1844 по 19-е декабря 1849 г. У него жена Анна Григорьева, въроисповьданія православнаго». На основании обнаруженного недочета составитель заметки делает вполне оправданное умозаключение: «Позволительно, однако, усомниться въ подлинности этого билета ужъ потому, что жена Ө. М. Достоевскаго названа въ немъ “Анной Григорьевой”. Анна Григорьевна - вторая жена Достоевскаго, на которой онъ женился уже въ Петербургъ (первая жена Ф. М. Достоевского - Мария Дмитриевна Исаева, заключившая с ним брак в 1857 году. - К. С.)».

На л. 116 об. ноябрьских записей дневника 1895 года приводится газетная заметка с описанием омской жизни Ф. М. Достоевского в пору его пребывания на каторге («Изъ № 7069ํㅡㅁ отъ 2을 Ноября 1895 года - газеты Новое Время»). Наряду с Ф. М. Достоевским героем заметки также стал и «его товарищ по ссылке», петрашевец С. Ф. Дуров. Статья вышла под типичной рубрикой «Нового Времени» - «Среди газет и журналов», в которой цитировались отрывки из опубликованных в других печатных изданиях литературных 
новинок (очерков, воспоминаний, мемуаров, биографических свидетельств). Так, автором очерка, чьи материалы на этот раз были использованы в заметке, является г. Мартьянов, представитель «омского общества пятидесятых годов». Воссозданный им психологический портрет Федора Михайловича раскрывает читателю потаенные стороны характера писателя и перекликается с текстом другой заметки из аналогичной рубрики «Среди газет и журналов» (фрагменты воспоминаний Д. В. Григоровича). Только во втором случае речь идет об юношеских годах Ф. М. Достоевского. Заметка помещена среди декабрьских записей 1892 года. Сравним: 1) картина омской жизни писателя - «Всегда насупленный и нахмуренный, онъ сторонился вообще людей, предпочитая въ шумъ и гамъ арестантской камеры оставаться одинокимъ, дЂлясь съ кЂмъ-нибудь словомъ, какъ какой-нибудь драгоцънностью, только по надобности» (ДН1894-1895, 116 об.), 2) время обучения Ф. М. Достоевского в Инженерном Училище - «Ө. М. уже тогда выказывалъ черты необщительности, сторонился, не принималь участія въ играхъ, сидълъ, углубившись въ книгу, и искалъ уединеннаго мъста; вскорь нашлось такое мъсто и надолго стало его любимымъ: глубокій уголъ четвертой камеры, съ окномъ, смотръвшимъ на Фонтанку; въ рекреаціонное время его всегда можно было тамъ найти и всегда съ книгой» (ДН1891-1892, 119). Оба свидетеля ушедших событий отмечают сдержанность характера Федора Михайловича, его стремление к уединению, саморефлексии.

В 1896 году исполнилось 50 лет с момента выхода в свет повести Ф. М. Достоевского «Бедные люди». А. М. Достоевский не мог обойти вниманием данное событие. Доказательством этому служат как дневниковые комментарии автора, так и заметка М. Александрова из газеты «Новое Время» от 9믕 Января 1896 года, приуроченная к юбилею произведения (ДН1896, 3). Публикации объединяет два хронотопических плана - прошлого и настоящего: наравне с сообщением о грядущих торжествах в честь памятной даты, в ней присутствуют и выдержки из воспоминаний Ф. М. Достоевского о своем дебютном сочинении. Обращаясь к читателю, 
М. Александров выражает надежду на достойное празднование литературного юбилея: «Судя по тому, какъ встрбчено было первое произведеніе Ө. М. Достоевскаго полвбка назадъ корифеями литературы той эпохи, можно предполагать, что современные представители русской литературы и образованное русское общество 24-го января достойно помянутъ писателя, оставшагося вЂрнымъ до конца и украсившаго русскую литературу цълымъ рядомъ блестящихъ произведеній». Однако, как явствует из дневникового высказывания А. М. Достоевского от 27으을 января 1896 года, эти надежды не оправдались: запланированные в день юбилея чтения в ярославском артистическом кружке были отменены, а в Петербурге все действо ограничилось «скромным и малолюдным» молебном на могиле писателя («Что то неожиданно-странное случилось съ намъреніемъ чествовать память Ө. М. Достоевскаго по случаю $50^{\mathrm{In}}$ льтія его перваго сочиненія. Въ Ярославль не допустилъ этаго чествованія Попечитель Московск<аго > Учебнаго Округа, въ Петербургъ же состоялось только чествованіе на кладьбищъ, да и то авторы ръчей у могилы, были переписаны Полиціей, какъ значится въ прилагаемой выръзкъ. Что бы этотъ сонъ обозначалъ!» (ДН1896, 5 об.)). Вклеенная на том же листе газетная вырезка («Изъ <Новаго Времени> № $7151^{\text {го }}$ отъ $28^{\text {го }}$ Января 1896 года»), подытоживающая историю с юбилейными торжествами, замыкает сюжетно-тематическую линию анализируемых А. М. Достоевским событий.

Итак, жанр дневника отличается стилистическим многообразием. Появление газетно-публицистических заметок на страницах дневникового текста обусловлено как творческими, так и психологическими предпосылками автора: вопервых, автор социализирует личное высказывание, переводит его на новый уровень - публичности; во-вторых, тем самым он удовлетворяет внутреннюю эмоциональную потребность во внешнем соучастии, сопереживании, пересечении судьбоносных моментов своей жизни с ходом общего исторического времени. 


\section{Примечания}

* Исследование выполнено по гранту Министерства образования и науки России «Новые источниковедческие и текстологические исследования русской словесности ХIX-XX вв.» (№ 34.1126).

${ }^{1} \mathrm{Cp}$. соответствующую формулировку А. Зализняка: «...дневник это текст, который пишется не для публикации <...> (я имею в виду “настоящий” дневник, а не дневник как жанр художественной литературы) опубликованный дневник - уже нарушает границы жанра» $[3,163]$.

${ }^{2}$ Представляется любопытным спорный постулат А. Н. Алексеева, который классифицирует дневники по трем основным речевым компонентам - дневник души, духа и факта $[1,43]$. Первые два варианта дневникового текста обращены к внутреннему миру автора, где «дневник души» представляет наиболее традиционный, канонический образец жанра (автор ведет дневник для себя), а «дневник духа» - это творческая лаборатория авторского сознания (автор преломляет документальную стилистику текста и привносит элементы художественности). «Дневник факта», по мнению исследователя, в наибольшей степени из озвученных субжанровых изводов привязан к внешним событиям жизни. На наш взгляд, подобная классификация избыточна, поскольку, в зависимости от литературной потребности автора, его сознание обнаруживает себя попеременно во всех трех указанных стилистических комбинациях. В данном случае правильнее бы было сказать о возникающей речевой доминанте стилистически цельного дневникового текста, а не о множественности психологических моделей авторского высказывания.

${ }^{3}$ Наша мысль подкрепляется и внутренней стилистической противоречивостью газетно-публицистического жанра: широкая информативность материалов всегда перемежается с личным опытом читателя. См., например, высказывание Т. А. Ленковой: «Для понимания содержания статьи адресат должен представить, о чем эта статья. Читая каждый раз все новый и новый материал, адресат постоянно обращается к своему личному опыту, личным знаниям, касающимся темы написанного» $[5,96]$.

${ }^{4}$ Достоевский А. М. Дневник 1891-1892 гг. // РО ИРЛИ. Ф. 56. Ед. хр. 6. Дневники А. М. Достоевского (далее - ДН) цитируются в тексте статьи с указанием года и листа (в архивной пагинации) в круглых скобках. С материалами дневников можно познакомиться на сайте philolog. petrsu.ru: [Электронный pecypc]. URL: http://philolog.petrsu.ru/amdost/ diaries/diaries.htm (12.08.2015).

${ }^{5}$ Здесь и далее все подчеркивания автора мы обозначаем курсивом; прочие случаи маркирования текста оговариваются отдельно. 


\section{Список литературы}

1. Алексеев А. Н. Дневник и письмо как формы социальной коммуникации // Философские науки. - № 8. - 2008. - С. 31-47.

2. Бикмуканова С. И. Публицистический стиль и его функционирование // Science Time. - 2014. - № 2 (12). - С. 35-38.

3. Зализняк А. А. Дневник: к определению жанра // Новое литературное обозрение. - 2010. - № 106. - С. 162-180. [Электронный ресурс]. - URL: http://magazines.russ.ru/nlo/2010/106/za14.html (10.08.2015).

4. Костомаров В. Г. Языковой вкус эпохи. Из наблюдений за речевой практикой масс-медиа. 3-е изд, испр. и доп. - СПб: Златоуст, 1999. $320 \mathrm{c}$.

5. Ленкова Т. А. К проблеме публицистического стиля и письменного дискурса СМИ // Вестник Челябинского государственного университета. - 2010. - № 13 (194). Филология. Искусствоведение. Вып. 43. - С. 94-98.

6. Михеев М. Ю. Фактографическая проза или пред-текст. Дневники, записные книжки, «обыденная» литература // Человек. - 2004. № 2. - С. 133-142.

7. Михеев М. Ю. Фактографическая проза или пред-текст. Дневники, записные книжки, «обыденная» литература // Человек. - 2004. № 3. - С. 132-143.

8. Рейнгольд А. С. Жанровые особенности литературного дневника и дневник как нелитературный текст // Вестник РГГУ. - 2010. № 11 (54). - С. 118-129.

Klavdiya V. Sizyukhina

Petrozavodsk State University (Petrozavodsk, Russian Federation) klasizz@yandex.ru

\section{THE FRAGMENTS OF NEWSPAPER PUBLICATIONS IN THE CONTEXT OF A. M. DOSTOEVSKY'S DIARIES}

Abstract: The article considers the functional and stylistic features of the intertextuality between the diary and newspaper genres within A. Dostoevsky's diaries. The combination of both genres is based on the artistic and poetic peculiarities of the diary text. A. Dostoevsky applies to newspaper publications within his diaries for the adding artistic dynamics to the text. First of all, the author refers correlates destinies of his family members (i. e. sister Varvara Karepina and brother Fyodor Dostoevsky, 
the elder son Alexander) with the historical circumstances of the epoch. In the biographical episodes and represent syncretism of the author's inmost psychological time with the historical process. Widening the stylistic space of the diaries A. Dostoevsky expresses his feelings outside, changes the poetical communication of the text - from intimacy to publicity. The biographical newspaper publications don't break the plot and thematic line of the diary notes, but complete their content. Secondly, A Dostoevsky includes in the narrative a lot of newspaper articles that are not directly connected with his family history. They cover the epochal historical events, for example: international chronicle, phenological notes (so-called "Bulletins of nature" by D. Kaygorodov), reminiscences about famous writers, military figures of the past, members of the royal families, various statistics, facts and so on. Thus, the newspaper notes (both biographical and public) enlarge social and cultural context of A. Dostoevsky's diaries. Personal history of Dostoevsky becomes particularly important for that epoch.

Keywords: diary, publicistic newspaper notes, genre, style, A. M. Dostoevsky, V. M. Karepina, F. M. Dostoevsky

\section{References}

1. Alekseev A. N. Dnevnik i pis'mo kak formy sotsial'noy kommunikatsii [Diaries and letters as a form of social communication]. Filosofskie nauki [Philosophical Sciences], 2008, no. 8, pp. 31-47.

2. Bikmukanova S. I. Publitsisticheskiy stil' i ego funktsionirovanie [Publicistic style and its functionality]. Science Time. 2014, no. 2 (12), pp. 35-38.

3. Zaliznyak A. Dnevnik: k opredeleniyu zhanra [Diary: the Definition of the Genre]. Novoe literaturnoe obozrenie [New Literary Review], 2010, no. 106, pp. 162-180. Available at: http://magazines.russ.ru/nlo/2010/106/ zal4.html (accessed 10 September 2015).

4. Kostomarov V. G. Yazykovoy vkus epokhi. Iz nablyudeniy za rechevoy praktikoy mass-media [The linguistic taste of the era. Observations of speech practice of mass-media]. Saint-Petersburg, Zlatoust Publ., 1999. $320 \mathrm{p}$.

5. Lenkova T. A. K probleme publitsisticheskogo stilya i pis'mennogo diskursa SMI [On the problem of publicistic style and written discourse of mass-media]. Vestnik Chelyabinskogo gosudarstvennogo universiteta [The messenger of Chelyabinsk State University], 2010, no. 13 (194), issue 43, pp. 94-98.

6. Mikheev M. Yu. Faktograficheskaya proza ili pred-tekst. Dnevniki, zapisnye knizhki, «obydennaya» literatura [Factual Prose or Pre-text: Diaries, Notebooks and "Everyday Literature"]. Chelovek [The Human being], 2004, no. 2, pp. 133-142. 
7. Mikheev M. Yu. Faktograficheskaya proza ili pred-tekst. Dnevniki, zapisnye knizhki, «obydennaya» literatura [Factual Prose or Pre-text: Diaries, Notebooks and "Everyday Literature"]. Chelovek [The Human being], 2004, no. 3, pp. 132-143.

8. Reyngol'd A. S. Zhanrovye osobennosti literaturnogo dnevnika i dnevnik kak neliteraturnyy tekst [Genre Features of the Literary Diary and the Diary as Non-Literary Text]. Vestnik rossiyskogo gosudarstvennogo gumanitarnogo universiteta [The Messenger of the Russian State University for the Humanities], 2010, no. 11 (54), pp. 118-129.

Дата поступления в редакцию: 31.08.2015 